\title{
A Comparative Study of the Photodegradation of Two Series of Cyclic Olefin Copolymers
}

\author{
Mario H. Gutiérrez-Villarreal and Sara A. Zavala-Betancourt \\ Centro de Investigación en Química Aplicada, Departamento de Procesos de Transformación de Plásticos, \\ Blvd. Enrique Reyna Hermosillo No. 140, Col. San Jose de los Cerritos, 25294 Saltillo, COAH, Mexico \\ Correspondence should be addressed to Mario H. Gutiérrez-Villarreal; mario.gutierrez@ciqa.edu.mx
}

Received 9 January 2017; Revised 23 March 2017; Accepted 24 April 2017; Published 13 July 2017

Academic Editor: Bernabé L. Rivas

Copyright ( 2017 Mario H. Gutiérrez-Villarreal and Sara A. Zavala-Betancourt. This is an open access article distributed under the Creative Commons Attribution License, which permits unrestricted use, distribution, and reproduction in any medium, provided the original work is properly cited.

\begin{abstract}
A series of commercial cyclic olefin copolymers (COC), namely, ethylene-norbornene (E-NB) and ethylene-tetracyclododecene (ETD), were processed as thin films with thicknesses of $25 \mu \mathrm{m}$ by an extrusion process. The photodegradation of neat and formulated films with different metal stearates ( $\mathrm{Fe}, \mathrm{Co}$, and $\mathrm{Mn}$ ) was investigated using an ultraviolet (UV) light lamp ( $340 \mathrm{~nm}$ ) for a period of 30 days in an accelerated weathering tester model QUV from Q-LAB according to the ASTM D 5208-01 standard practice. Changes in carbonyl index (CI) and tensile properties were used to evaluate the photodegradation of the films and other properties, such as $T g$ variation by DSC, were also analyzed. The present study reveals that (E-NB) copolymers show higher sensitivity to photodegradation than (E-TD) resins, in the absence and presence of metal stearates. We also find that the Fe salt shows the highest oxidative activity.
\end{abstract}

\section{Introduction}

Polyolefins are the most produced and consumed synthetic polymers worldwide, with many uses such as packaging, toys, appliances, and disposable items. As a result of their high stability and resistance to degradation, these compounds have accumulated in the environment, contributing to many ecological and pollution problems. Natural weathering (including solar radiation), wind, and ambient temperatures lead to the formation of free radicals in these compounds, when combined with oxygen. The oxidative degradation process may take many years to reach complete degradation. The technologies most commonly used to accelerate the degradation process [1] involve the use of prooxidant additives (POA) to make polyolefins oxobiodegradable [2].

Polymer photodegradation and stabilization are extensive fields of study. It is well established that photooxidation reactions play an important role in the degradation process of ultraviolet (UV) irradiated polymeric materials, and the controlling mechanisms have been studied by some authors [3-5]. The physicochemical changes which occur during photooxidative reactions are characterized by an increase in the concentration of the oxygen-containing groups such as peroxides, hydroperoxides, and ketonic carbonyl groups [6]. However, cross-linking and chain secession processes, detected during a study of photooxidation in polyethylene, are believed to be sources of great importance in causing changes in the mechanical properties of polyolefins [7].

Nowadays, several authors have already studied the influence of (POA) on the photooxidation of polymers; for instance, Pablos and coworkers [8] studied the effect of iron and calcium stearates on the photodegradation of polyethylene (LDPE and LLDPE) under natural and artificial exposure using chemiluminescence. Changes in chemical structure were monitored through Fourier transform infrared spectroscopy (FTIR) and gas chromatography-mass spectrometry (GC-MS) was used to follow changes in molecular weight and the content of degradation products. Ojeda et al. [9] prepared different films from high density polyethylene (HDPE), linear low density polyethylene (LLDPE), and isotactic polypropylene (PP) containing antioxidant additives and exposed them to natural weathering for one year, during which their structure, thermal, and mechanical properties were monitored. Roy and coworkers $[10,11]$ used cobalt and manganese stearates to study the photo and thermooxidative degradations of LDPE and LLDPE. The study showed that 
TABLE 1: Description and properties of cycloolefin copolymers used in this study (data provided by the suppliers).

\begin{tabular}{lccccccc}
\hline Supplier & Code & $\mathrm{Tg}^{\circ} \mathrm{C}$ & \% of NB units & \% of TD units & $\begin{array}{c}\text { Density } \\
\text { g-cm }^{-3}\end{array}$ & MFI g/10 min $^{\mathrm{a}}$ & Series $^{\mathrm{b}}$ \\
\hline Topas $^{\circledR}$ & 6013 & 140 & 54.3 & & 1.02 & 1.00 & $\mathrm{D}$ \\
Topas & 8007 & 80 & 37.6 & 21.6 & 1.02 & 1.70 & $\mathrm{D}$ \\
Apel & 6509 & 80 & & 1.02 & 1.51 & $\mathrm{~A}$ \\
Apel & 8008 & 70 & & 1.02 & $\mathrm{~A}$ \\
\hline
\end{tabular}

${ }^{\mathrm{a}}$ At $190^{\circ} \mathrm{C}$ and $2.16 \mathrm{Kg} ;{ }^{\mathrm{b}}[12]$.

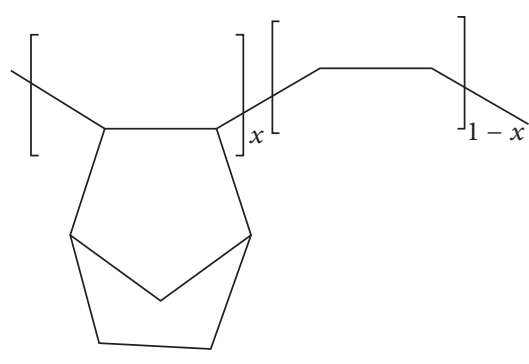

(a)

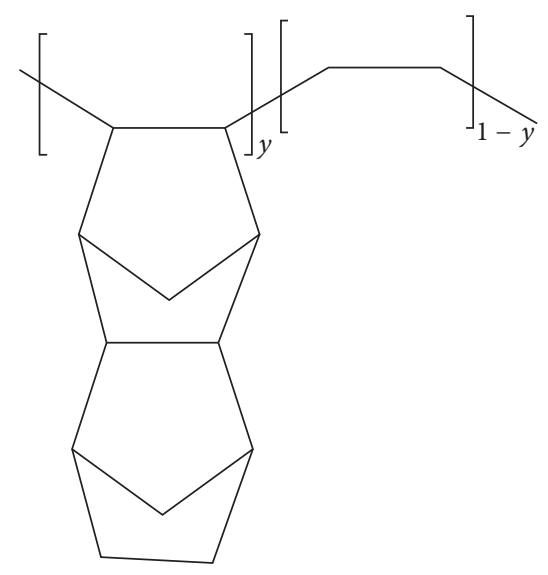

(b)

Figure 1: Structure of COC copolymers. (a) Ethylene-norbornene (E-NB) copolymer: Series D. (b) Ethylene-tetracyclododecene (E-TD) copolymer: Series A.

the durability of the olefin polymers was less than one year, as a consequence of severe oxidative degradation. The main factors influencing the degradability were the frequency of tertiary carbon atoms in the chain and the presence of POA.

Zalikha and coworkers [12] studied the effect of cobalt stearate on photooxidative aging of polypropylene film, reporting the changes in tensile properties and carbonyl index. In their work, they concluded that the rate of degradation was enhanced and dependent on the concentration of cobalt stearates.

Cycloolefin copolymers (COCs) form a new class of copolymers which possess excellent properties, such as totally amorphous structure, a high glass transition temperature, excellent mechanical and optical properties, high decomposition temperature, and good moisture barrier, making them a potential replacement in some engineering polymers. These novel copolymers have diverse applications in optical fibers, electrical appliances, automotive parts, containers, bottles, compact disks, and packaging films.

As a film, COC resins offer significant advantages over existing products, especially when high water vapor barrier, clarity, and rigidity are required [13]. Their applications cover a broad spectrum ranging from high moisture barrier packaging films to technical films capacitors [14, 15]. Shrink films for sleeves and flexible films based on blends of COCs with low density polyethylene have also been developed [16].

Recently, there have been many articles devoted to the investigation of the structure and mechanical properties of these new COCs using standard investigative methods; however, scarce research on their photo- and thermal degradation has been completed, compared with similar products made from olefin polymers. The aim of this investigation is to make a comparative study of stability under the influence of UV irradiation of two neat and metal formulated series of COCs.

\section{Experimental}

2.1. Materials. COCs (6013 and 8007) supplied by Ticona (Kelsterbach, Germany) and COCs (6509 and 8008) from Apel (Mitsui Chemicals, Inc.) were used for the preparation of the thin films. Some physical properties of these two copolymers are listed in Table 1 and are represented by structures (a) and (b), respectively, in Figure 1 [17]. Prooxidant additives, as a master batch of three different transition metal (Fe, Co, and $\mathrm{Mn}$ ) stearates, were provided by different suppliers ( $\mathrm{d} 2 \mathrm{w}$ : from Symphony Environmental Ltd.; Reverte BD93470: from Wells Plastics Ltd.; and EPI: from Environmental Products Inc.) and used as recommended for the production of commercial products (Table 2).

2.2. Sample Preparation. In this study, each COC was dry mixed with $1.0 \mathrm{wt} \%$ of each metal stearate and fed into a Killion single screw extruder KTS-100 (one-inch diameter and $L / D=24: 1$ ) at a constant screw speed of $100 \mathrm{rpm}$ and a collection rate of $5.4 \mathrm{~m} / \mathrm{min}$. For the Topas resin 6013 , the temperature settings for the extruder were feed zone, $220^{\circ} \mathrm{C}$; compression zone, $250^{\circ} \mathrm{C}$; metering zone, $260^{\circ} \mathrm{C}$; and die 
TABLE 2: Active metals and content of prodegradant agents in master batch.

\begin{tabular}{lcc}
\hline Prodegradant agent & Active metal & Metal content $(\mathrm{ppm})$ \\
\hline $\mathrm{d} 2 \mathrm{w}$ & Manganese & 3399 \\
Reverte & Iron & 659 \\
EPI & Cobalt & 9058
\end{tabular}

zone, $270^{\circ} \mathrm{C}$. For the rest of the copolymers, the temperature settings were feed zone, $190^{\circ} \mathrm{C}$; compression zone, $210^{\circ} \mathrm{C}$; metering zone, $210^{\circ} \mathrm{C}$; and die zone $230^{\circ} \mathrm{C}$. A $30.5 \mathrm{~cm}$ wide flexible lip die was adapted to produce the cast film; samples with a size of $1 \times 14 \mathrm{~cm}^{2}$ were cut for the aging process.

2.3. UV Aging Tests. The cycloolefin film samples were exposed to aging in a QUV accelerated weathering tester according to ASTM D 5208-01 for 30 days (720 hr) for photooxidative treatment. Single samples were withdrawn every five days and changes due to photooxidation were monitored by recording changes in mechanical properties and the molecular structure.

2.4. FTIR Analysis. Molecular changes upon UV light exposure were investigated using FTIR Avatar 330 Thermo Nicolet equipment. The test on the film was conducted using an IR band between $4000 \mathrm{~cm}^{-1}$ and $450 \mathrm{~cm}^{-1}$; spectra were made up of 25 scans with the resolution set to $4 \mathrm{~cm}^{-1}$. Carbonyl index (CI) was used to monitor the level of degradation of the cycloolefins. It is defined as the ratio of absorbance of the carbonyl band at $1680-1840 \mathrm{~cm}^{-1}$ (which is a by-product of the photooxidation) and internal thickness absorption band at $1456 \mathrm{~cm}^{-1}$. These have been calculated by the baseline method $[18,19]$.

Carbonyl Index (CI)

$$
=\frac{\text { Absorption at the maximum of carbonyl band }}{\text { Absorption at } 1456 \mathrm{~cm}^{-1} \text { (internal thickness band) }} \text {. }
$$

2.5. Tensile Tests. Tensile tests for all samples were evaluated according to ASTM D882 method at room temperature. Tests were performed on films with a constant thickness of $25 \mu \mathrm{m}$ and same dimensions $1 \times 14 \mathrm{~cm}^{2}$ using an Instron 4301 tensile tester with a load cell of $500 \mathrm{~N}$ with a $0.1 \mathrm{~N}$ sensitivity and an electrical sensitivity of $1.6 \mathrm{mV} / \mathrm{V}$ with a constant cross head speed of $0.50 \mathrm{~cm} / \mathrm{min}$. An average value from five tested samples was taken for each film.

2.6. DSC Analysis. DSC tests were conducted using a Q200 TA Instruments calorimeter, under a nitrogen flow of $100 \mathrm{ml} / \mathrm{min}^{-1}$. The samples were first heated from 20 to $350^{\circ} \mathrm{C}$ at $10^{\circ} \mathrm{C} / \mathrm{min}^{-1}$ and held at $350^{\circ} \mathrm{C}$ for $1 \mathrm{~min}$ to delete thermal history. After that, the samples were cooled down to $20^{\circ} \mathrm{C}$ with a cooling rate of $20^{\circ} \mathrm{C} / \mathrm{min}$ and held at $20^{\circ} \mathrm{C}$ for $1 \mathrm{~min}$. The second run was performed by heating the sample to $350^{\circ} \mathrm{C}$ under the same conditions as the first run; these scanning steps can be seen for Topas 6013 resin in Figure 2. On the first run we can appreciate some stresses built into

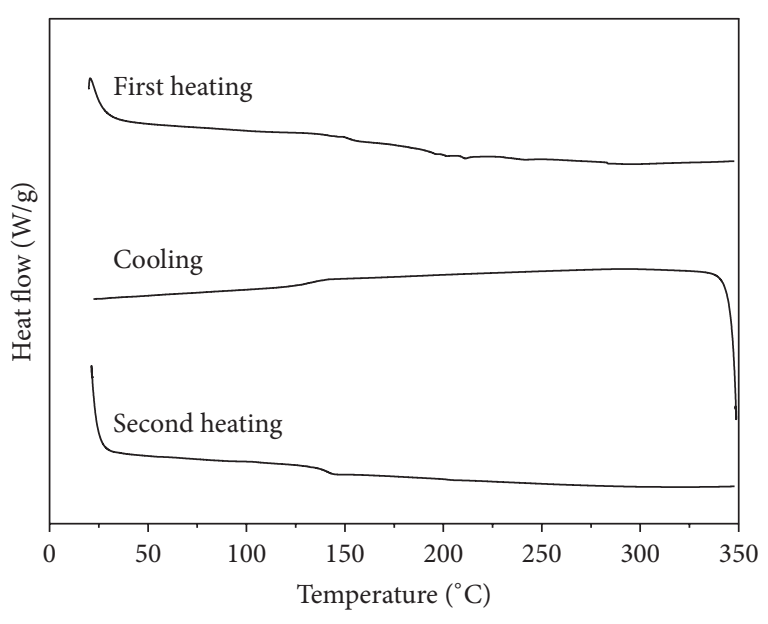

FIGURE 2: DSC traces of the Topas 6013 resin.

the material as a result of processing, handling, or thermal history around $140^{\circ} \mathrm{C}$ (related to the glass transition) and on the region of $200-275^{\circ} \mathrm{C}$ which are released when the material is heated through its glass transition.

The data used in this publication were taken from the second heating to evaluate the glass transition temperature $(\mathrm{Tg})$ of each copolymer with and without metal stearates after aging. On a previous work [20] we published the high thermal stability of these cycloolefin resins with a decomposition temperature above of $450^{\circ} \mathrm{C}$. The very low $\mathrm{CI}$ values and the little difference on the mechanical properties reflected on the percent in elongation at break indicate a good stability to oxidation even under the presence of prodegradant additives at the thermal aging conditions. Similar results on thermal stability of cycloolefins have been reported by Yang and coworkers [21] and an investigation on the role of metal stearates on the degradation behavior of LDPE has been published by Roy and coworkers [22].

\section{Results and Discussion}

Physicochemical changes which occur during photooxidative reactions are characterized by an increase in the concentration of the oxygen-containing groups such as peroxides, hydroperoxides, and also the ketonic carbonyl groups [23, 24]. However, cross-linking and chain scission processes occurring during photooxidation in polyolefins are believed to be sources of great importance in causing changes in the mechanical properties of these materials [25]. Normally, it has been reported [26] that initial values of mechanical properties are not affected by the incorporation of POA additives, thereby implying that these additives do not led to degradation until being activated by UV light or high temperatures.

3.1. FTIR Studies. The relative effects of the transition metal additives on the photodegradation of the series of cycloolefins were compared by simultaneous irradiation on the neat and formulated films using UV light in a QUV accelerated weathering tester. As shown in Figure 3, the infrared spectrum 


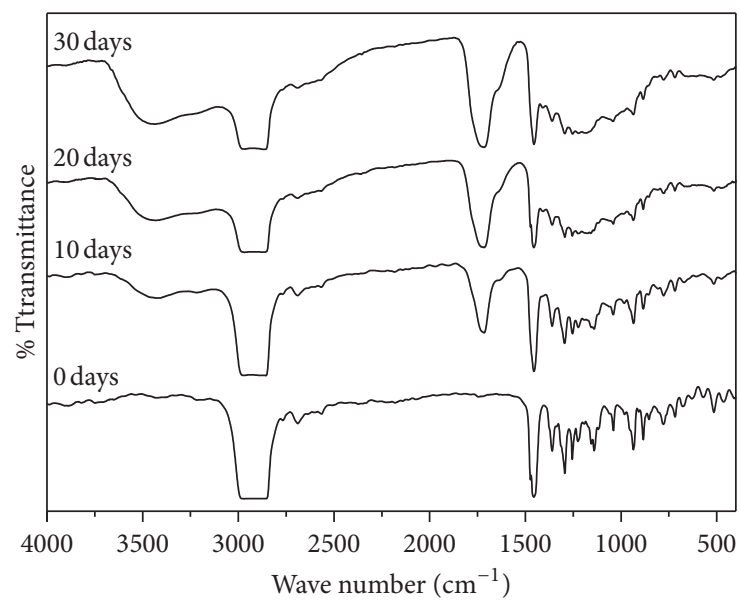

FIGURE 3: Change in IR of COC 6013 neat film during photoirradiation.

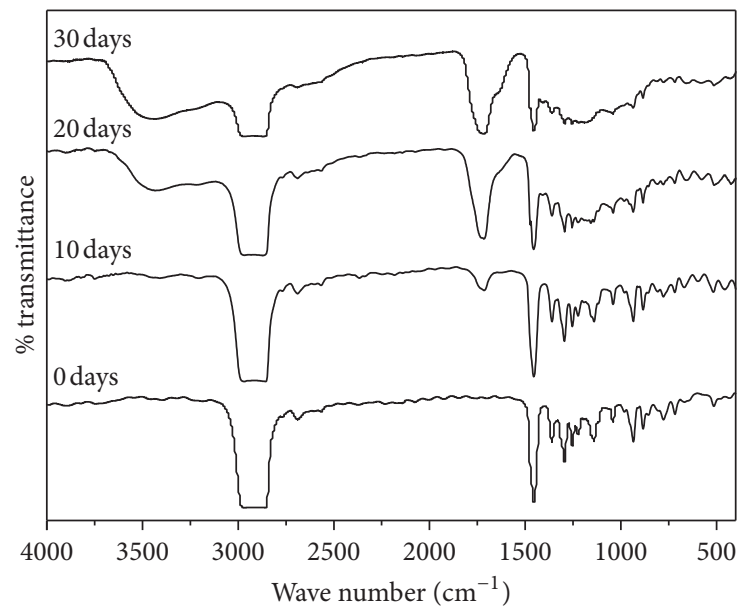

FIGURE 4: Change in IR of COC 6013 containing Fe prodegradant during photoirradiation.

of a COC 6013 neat film changes remarkably in the regions of ca. $1720 \mathrm{~cm}^{-1}$ due to carbonyl groups, $3300-3400 \mathrm{~cm}^{-1}$ due to hydroxyl groups, ca. $1300 \mathrm{~cm}^{-1}$ due to an amorphous region, and ca. $909 \mathrm{~cm}^{-1}$ due to unsaturated groups after 30 days of UV irradiation. The presence of the vinyl signal $\left(909 \mathrm{~cm}^{-1}\right)$ could be explained that during the extrusion process in presence of air and high temperature an eventual degradation of the resin by thermooxidation gives rise to this signal $[27,28]$. The absorption band around $1714 \mathrm{~cm}^{-1}$, which can be assigned to the stretching of $>\mathrm{C}=\mathrm{O}$ functionalities, increases in intensity and broadened substantially, indicating the presence of multiple oxidation products $[29,30]$.

In addition, infrared spectra of COC films containing prodegradant additives are shown in Figure 4, where the extent of the changes in these regions of the infrared spectra is apparently affected by metal additives present on the sample films.

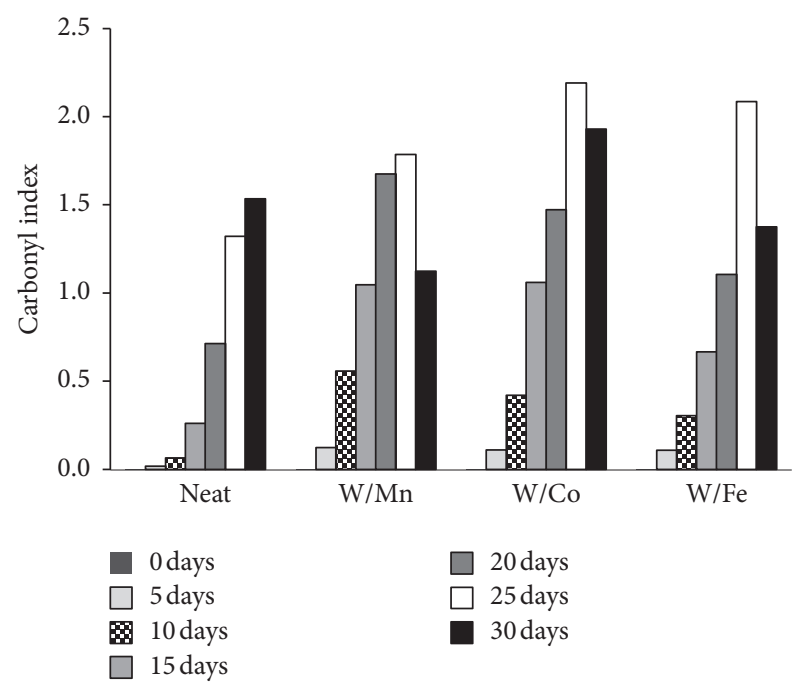

FIgURE 5: Increase in the carbonyl index of Topas 6013 COC neat and formulated films during exposure to QUV irradiation.

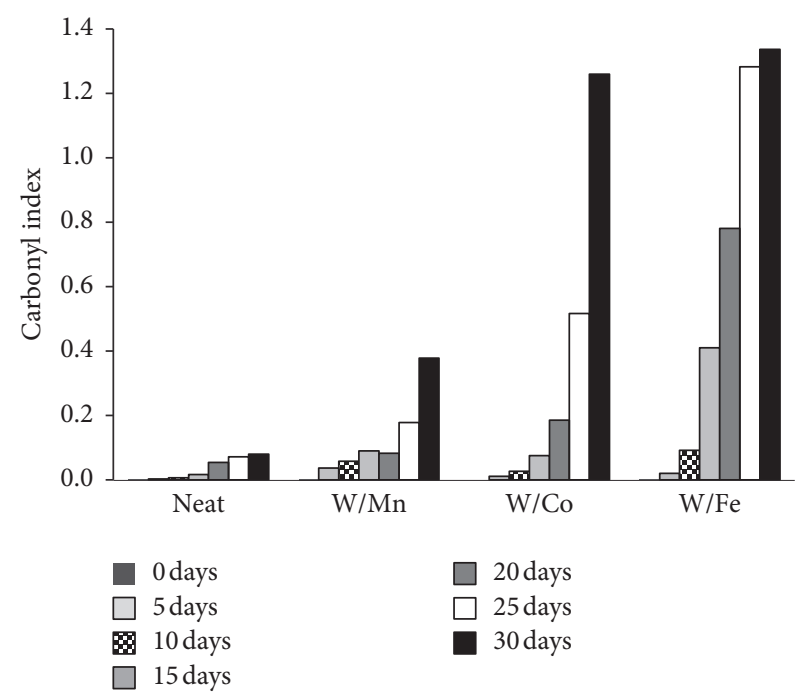

FIgURE 6: Increase in the carbonyl index of Topas 8007 COC neat and formulated films during exposure to QUV irradiation.

The extent of degradation of these samples under the influence of metal additives has been quantified by calculating the $\mathrm{CI}$, which is the ratio of the intensity of signals $\left(1740 / 1456 \mathrm{~cm}^{-1}\right)$ at different times of exposition. This increase in CI with time of exposure indicates an advance of the degradation reaction, as a result of the decomposition reactions of peroxides and hydroperoxides generated by the formation of free radicals responsible for the beginning of the degradation process, which has been observed on other polyolefins $[22,31]$. Figures $5-8$ represent the change in the $\mathrm{CI}$ as a function of exposure time of UV light on the neat and formulated films.

We can see in Figure 5 that the Topas COC 6013 film is relatively more susceptible to degradation even without metal stearates and this can be explained by the presence 


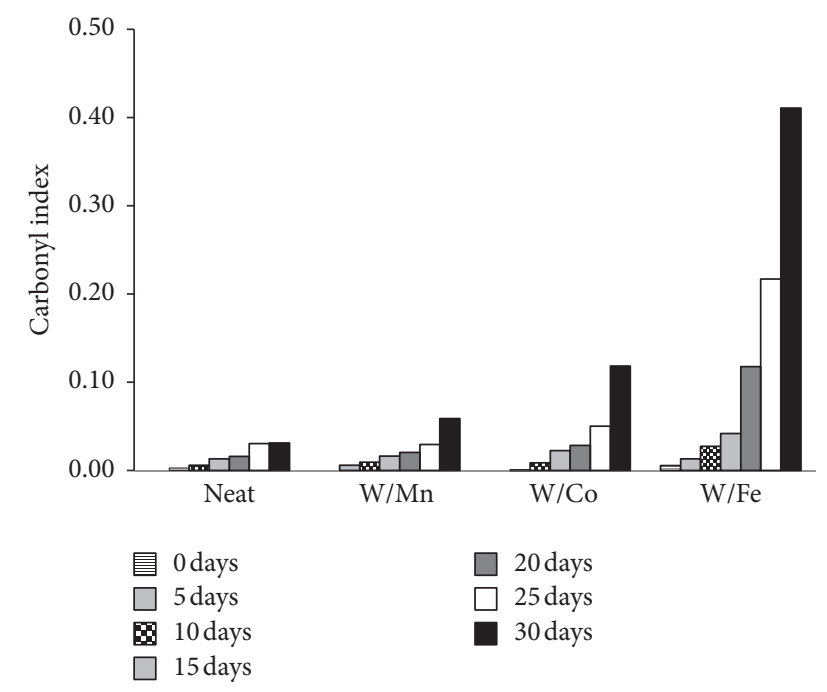

FIGURE 7: Increase in the carbonyl index of Apel 6509 COC neat and formulated films during exposure to QUV irradiation.

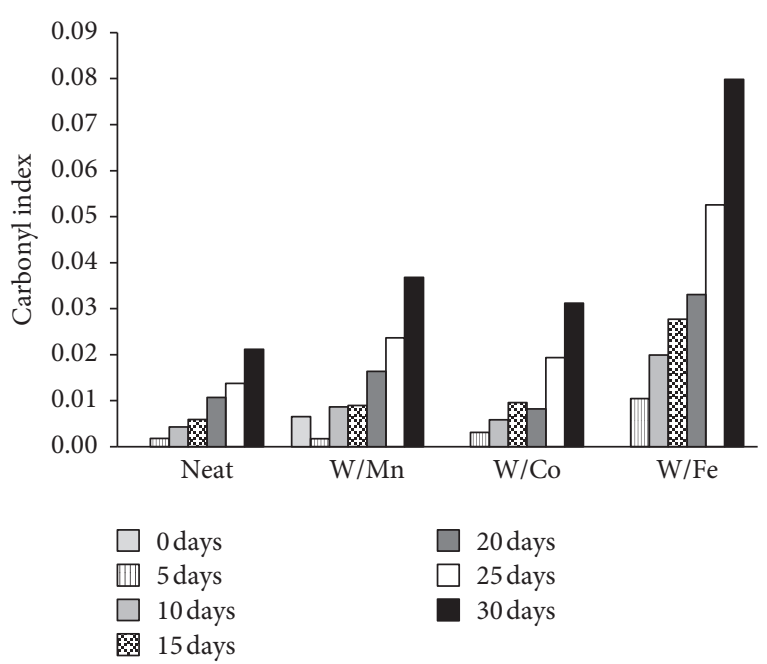

FIGURE 8: Increase in the carbonyl index of Apel 8008 COC neat and formulated films during exposure to QUV irradiation.

of a large number of norbornene units on the backbone copolymer, which increases the number of tertiary weak sites for oxidation [32]. Also it is observed that at 30 days of exposure the carbonyl index decreases when it is formulated with the three stearates; this reduction can be explained to the fact that the degradation is occurring through a stage in which the cross-linking predominates more than molecular excision, since these two phenomena are happening simultaneously as it was reported by Kyrikou et al. [33] and by Nikolic and coworkers [34], when cross-linking predominates, species with carbonyl groups are reduced. Also, Wypych [35] reports that the concentration of $\mathrm{C}=\mathrm{O}$ decreases during exposure to UV light because this functional group is susceptible to undergoing photooxidation reactions by UV radiation effects, so the carbonyl index decreases. Another explanation for this behavior could be that the

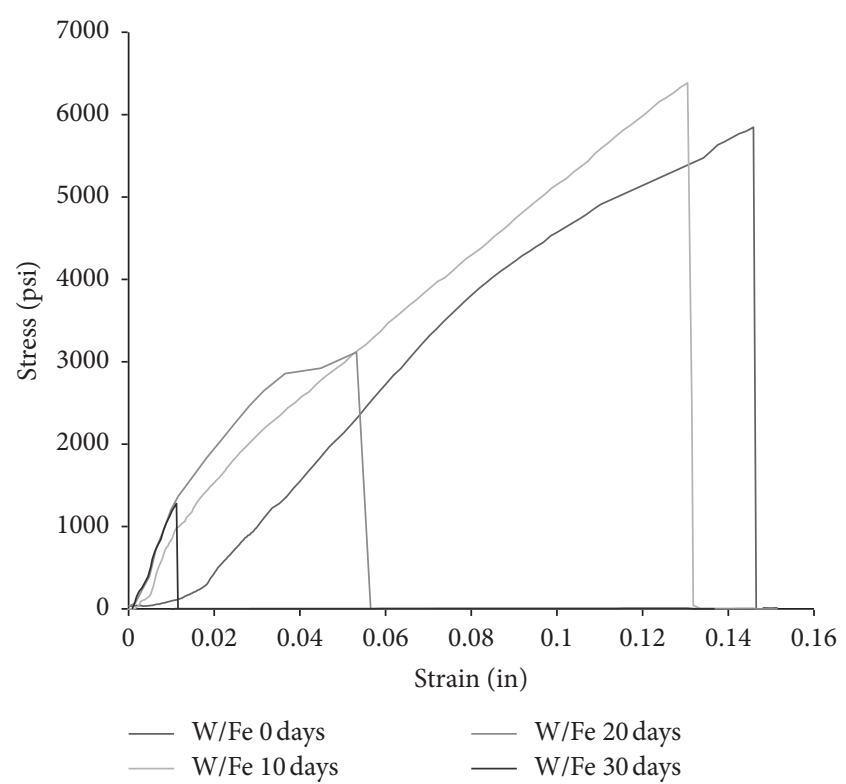

Figure 9: Stress-strain curve for the Apel 6509 resin with $\mathrm{Fe}$ additive.

photolysis of carbonyl products (such as carboxylic acids, aldehydes, and/or lactones) to volatile products leads to a lower concentration of oxidation products in the polymer during photodegradation [36].

With respect to the two evaluated series, the Apel 8008 COC copolymer showed higher photooxidative stability, even in the presence of prooxidants, as can be seen by the lower values of the CI during the aging time, and this stability is associated with the low norbornene content, which implies lower C-H labile bonds.

By comparing the prooxidant nature of the three stearates on both series of COCs, we can conclude that the Fe and Co stearates are more active than the Mn stearate.

3.2. Mechanical Properties. Elongation at break of the films was evaluated at regular time intervals to monitor the degradation behavior, as it has been considered to be a direct indicator of this property $[37,38]$. Figure 9 presents a stressstrain curve for the Apel 6509 resin with Fe additive showing the loss of the mechanical properties during 30 days of UV aging. Figures 10-17 present the effect of photooxidation on elongation at break and tensile stress at break of neat and formulated films. The elongation at break values decreased for the neat samples and for those containing metal stearate salts, the rate is much faster in the case of Fe and Co metals.

Photooxidation is a process where competition between bond breaking and cross-linking happens during aging and this can explain the low and high values of elongation of the samples. The Topas 6013 COC films containing metal stearates became completely fragile after 15 days of photooxidation treatment and could not be tested further. However, it is noted here that the elongation values of neat Topas COC films dropped faster than those of the Apel copolymers, which means that the former are less stable to photooxidation due to the presence of high content of norbornene rings and 


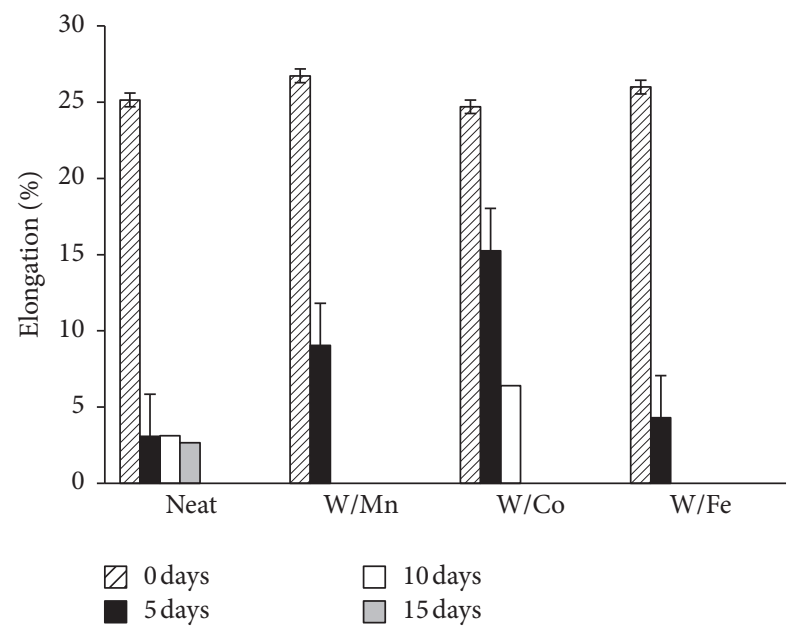

FIgURE 10: Elongation at break of Topas 6013 COC neat and formulated film with different POA.

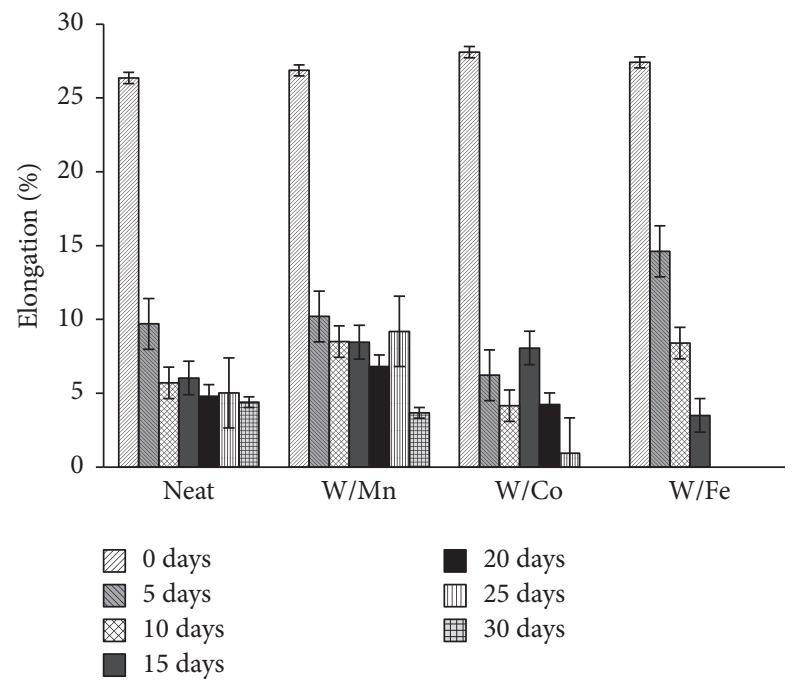

Figure 11: Tensile stress at break of Topas 6013 COC neat and formulated films with different POA.

therefore higher content of tertiary carbons susceptible to degradation.

Regarding tensile stress properties, an erratic trend in the strength values with the progress of the degradation process for the different formulations is observed in Figures 11,13,15, and 17; this behavior may be related to the mechanism of the degradation reaction and the stages through which this process occurs. The increase in tensile strength as the photodegradation takes place may be related to a reaction step in which cross-linking reactions predominate and the latter decrease is a result of chain scission $[23,39]$.

Tanaka and coworkers [40] published the effect of the morphology on the photodegradation of LDPE films with UV light and reported that chain scission lowers the molecular weight, whereas cross-linking reaction causes an increase in the higher molecular weight fraction and these changes

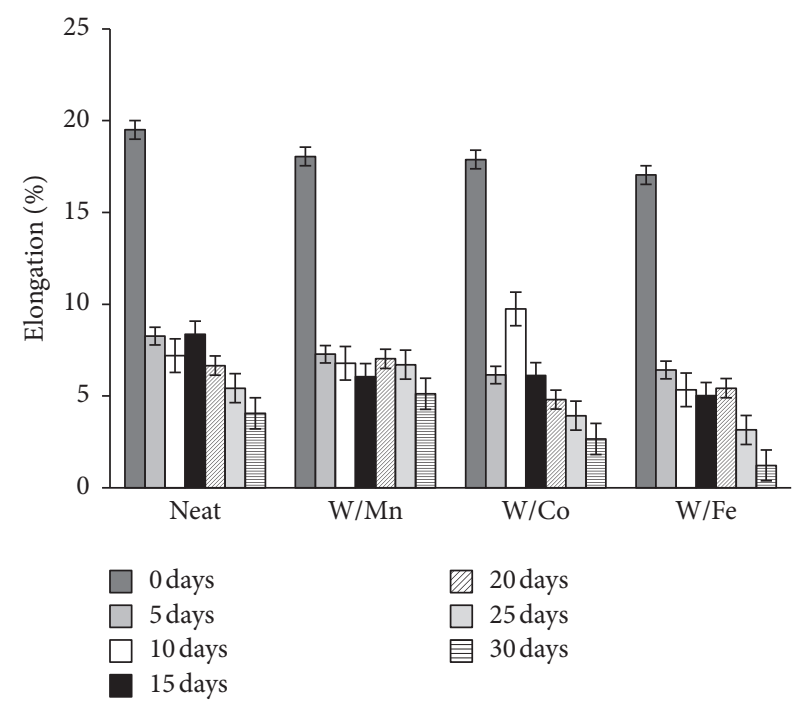

FIgURE 12: Elongation at break of Topas 8007 COC of neat and formulated films with different POA.

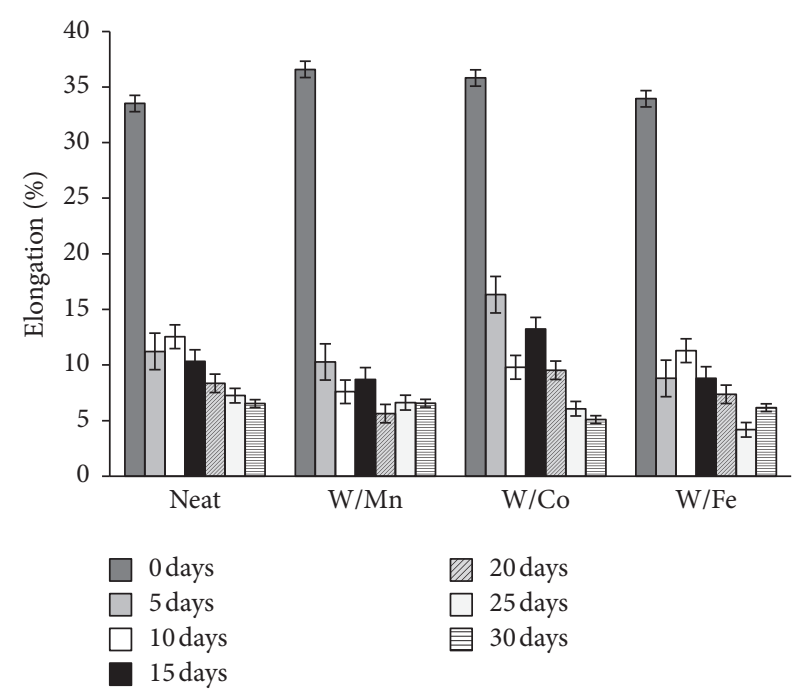

FIgURE 13: Tensile stress at break of Topas 8007 COC neat and formulated films with different POA.

which occurs simultaneously during photodegradation could explain the behavior reported on elongation and stress at break during aging.

The photooxidative behavior was found to depend upon the type of metal present in the COC matrix and follows the order of $\mathrm{Fe}>\mathrm{Co}>\mathrm{Mn}$.

3.3. Thermal Properties. DSC thermogram for the Topas 8007 resin is presented in Figure 18; this figure shows the first heating run, cooling, and second heating run. The first run shows a change of slope at $80.5^{\circ} \mathrm{C}$ with an apparent melting at glass transition $(\mathrm{Tg})$ due to the stresses built into the material as a result of processing, handling, or thermal history which are released when the material is heated through its glass transition. 


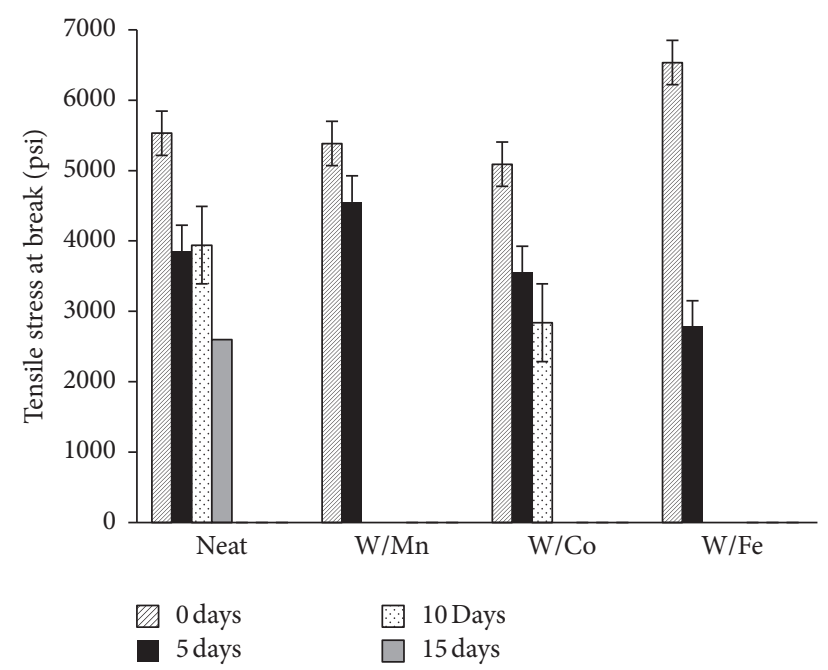

FIgURE 14: Elongation at break of Apel 6509 COC neat and formulated films with different POA.

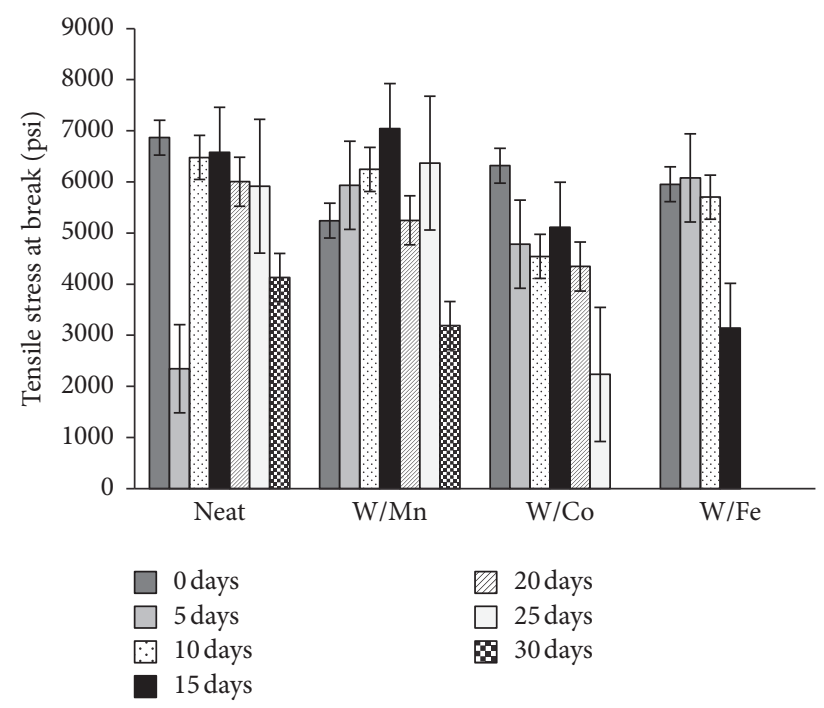

FIgURE 15: Tensile stress at break of Apel 6509 COC neat and formulated films with different POA.

During the quench cooling from $350^{\circ} \mathrm{C}$ to a temperature below $\mathrm{Tg}$, the thermogram does not show an exothermic signal associated with a crystallization phenomenon because the polymer is amorphous; however, a little change on the slope of the curve can be seen at $77.5^{\circ} \mathrm{C}$ due to the transition of the rubbery to glassy state of the polymer associated with the $\mathrm{Tg}$ temperature.

The second heating run after the internal stresses were relieved; the graph shows a change on the flow energy manifested by the presence of the glass transition at $79.7^{\circ} \mathrm{C}$ when the molecules go from a rigid to a flexible structure.

Figures 19 and 20 present the heating DSC traces of the neat and formulated COC samples after 30 days of aging; as shown, there exists a drop in the $(\mathrm{Tg})$ between the UV treated and untreated samples, which implies a chain scission of the copolymers which is accelerated by the influence of the

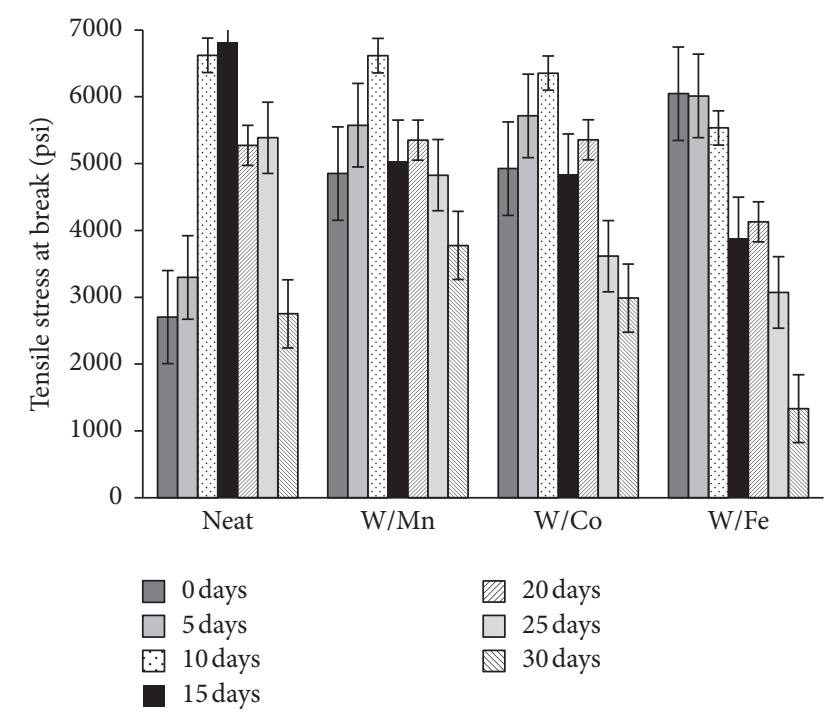

Figure 16: Elongation at break of Apel 8008 COC neat and formulated films with different POA.

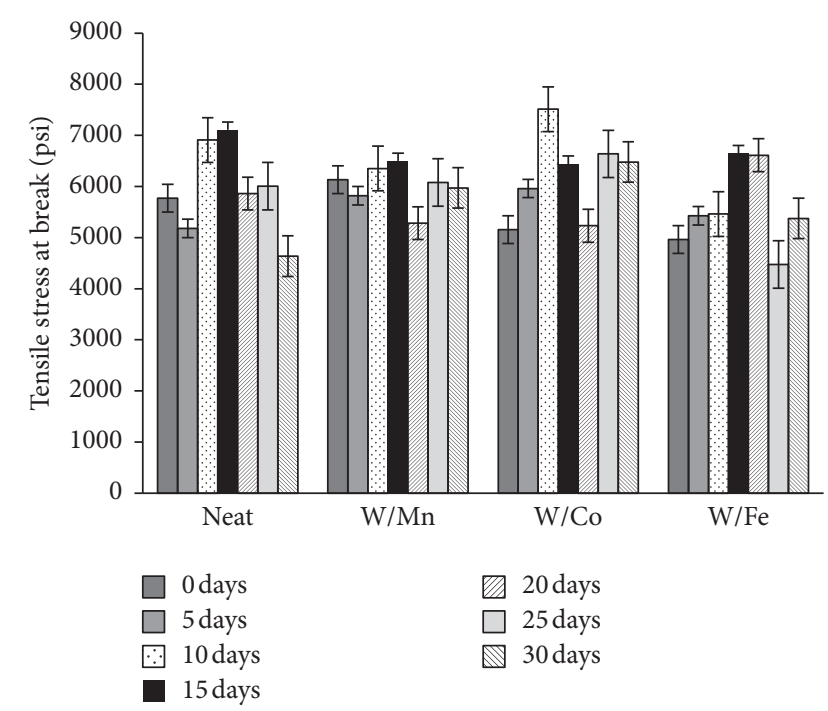

FIgURE 17: Tensile stress at break of Apel 8008 COC neat and formulated films with different POA.

prooxidant additives, as shown in Table 3 . Here, we can see that the Fe stearate shows the highest reactivity based on the higher difference on the drop of the $\mathrm{Tg}$ value, followed by Co and finally the Mn salt.

Table 3 also shows the $\mathrm{Tg}$ values obtained from the difference with the $\mathrm{Tg}$ of neat film, and as it is seen, the Apel 8008 COC resin shows the lowest change on $T g$ values in comparison with the other resins; this behavior could be associated with the great stability of its structure, which was observed by the lowest CI values in the Figure 8 ; its resistance to oxidation is due to the low content of norbornene rings and therefore lower content of tertiary carbons susceptible to degradation. However, even when the resin is stable to chemical oxidation, the generation of free radicals during treatment with UV light promotes cross-linking reducing the 
TABLE 3: $\mathrm{Tg}$ value of COC films formulated with different prooxidant additives after 30 days aging under UV light.

\begin{tabular}{lcccccrr}
\hline & \multicolumn{2}{c}{${ }^{6013}$} & \multicolumn{2}{c}{8007} & \multicolumn{2}{c}{6509} & \multicolumn{2}{c}{8008} \\
& $\mathrm{Tg}\left({ }^{\circ} \mathrm{C}\right)$ & $\Delta{ }^{\circ} \mathrm{C}$ & $\mathrm{Tg}\left({ }^{\circ} \mathrm{C}\right)$ & $\Delta{ }^{\circ} \mathrm{C}$ & $\mathrm{Tg}\left({ }^{\circ} \mathrm{C}\right)$ & $\Delta{ }^{\circ} \mathrm{C}$ & $\mathrm{Tg}\left({ }^{\circ} \mathrm{C}\right)$ \\
\hline Neat film & 139.6 & & 79.7 & & 79.4 & 7.4 & 67.4 \\
UV treated film & 132.5 & 7.1 & 80.0 & 0.3 & 78.7 & 0.7 & 66.9 \\
w/Mn & 129.8 & 9.8 & 77.3 & 2.4 & 77.8 & 1.6 & 64.1 \\
w/Co & 128.5 & 11.1 & 74.3 & 5.4 & 76.2 & 3.2 & 64.6 \\
w/Fe & 128.3 & 11.3 & 72.1 & 7.6 & 75.8 & 3.6 & 64.6 \\
\hline
\end{tabular}

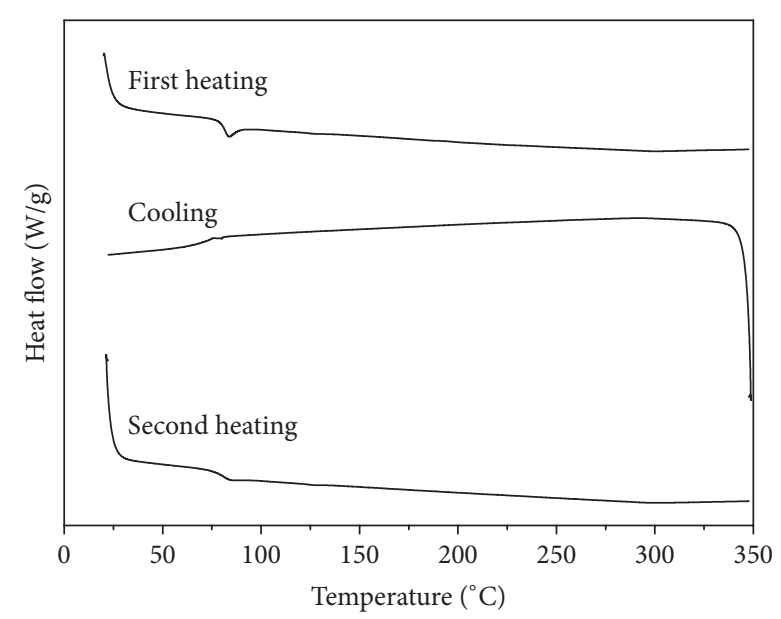

Figure 18: DSC traces of the Topas 8007 resin.

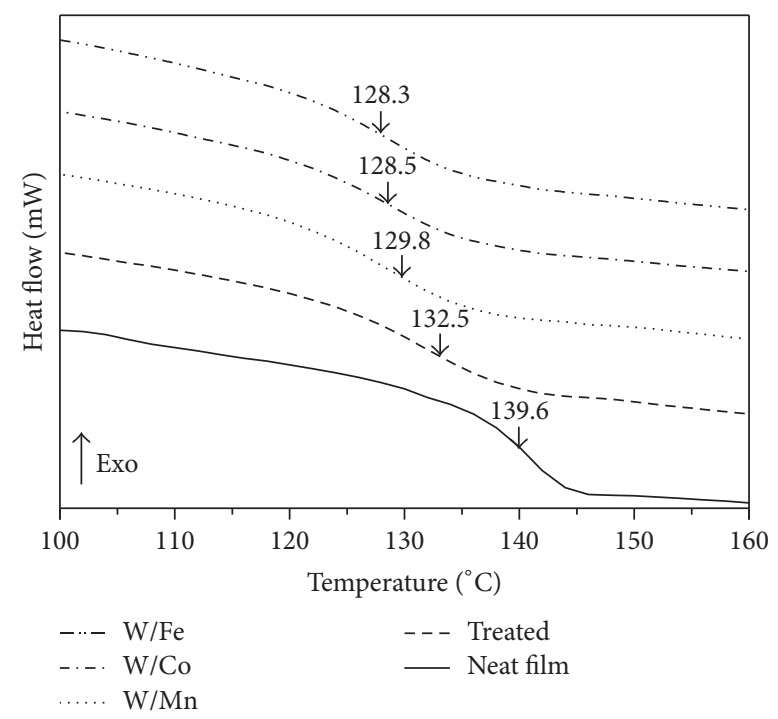

FIGURE 19: DSC traces of the Topas COC 6013 neat and formulated films with POA after 30 days of aging under photoirradiation.

molecular mobility by the chemical bonds formed between polymer chains, causing a decrease of the elongation against an effort [41] and stiffening of the film, making it a brittle film but retaining its thermal properties, with a little noticeable change in $\mathrm{Tg}$.

The degradation process of a polymeric material can occur through several mechanisms that bring about chemical

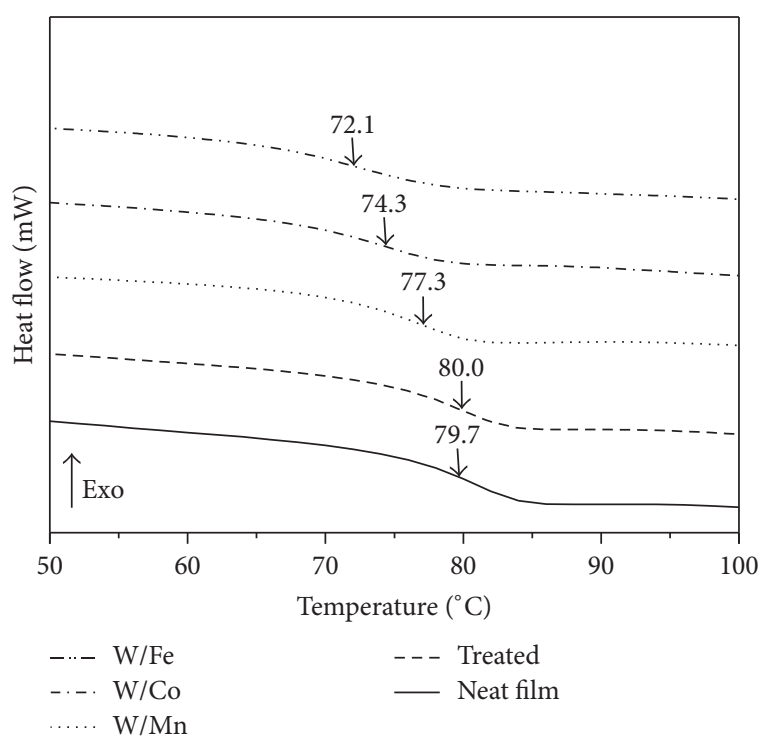

FIGURE 20: DSC traces of the Topas COC 8007 neat and formulated films with POA after 30 days of aging under photoirradiation.

and structural changes of the material affecting the mechanical properties of the material [42, 43]. Molecular scission, which has the direct effect of lowering the molecular weight, will reduce the elasticity of the material, while possible cross-linking reactions may cause stiffening of the polymer. These changes will be reflected in the mechanical properties, specifically in elongation and tensile strength. As it was shown in the figures of mechanical properties, even when the virgin resins showed loss of properties with aging, the presence of the POA additives accelerated the degradation process due to the generation of free radicals which catalyze the reaction.

Regarding the formation of carbonyls in the different resins, their presence was increased with the time of UV treatment; however, there exists no correlation between mechanical properties and Carbonyl index because tensile properties of films do not change at the same rate as carbonyl groups formation [44].

Kinetic study and mechanism of oxidation for this system are in progress and the results will be published later.

\section{Conclusions}

The present study reveals the different behavior of photostability for two cycloolefin series, in the presence and absence 
of oxidative salts, under UV irradiation. COC 6013 was found to be more susceptible to degradation than the rest of the copolymers due to the presence of a high percent of norbornene units in its structure, which increases the number of tertiary sites that are sensitive to UV irradiation and leads to the generation of free radicals, promoting the degradation of the copolymers.

Also, this work shows that Fe stearate had the highest effect on the cyclic olefin oxidation, followed by the Co and Mn salts, as observed by the carbonyl index, elongation, and $\mathrm{Tg}$ measurements. This behavior can be explained by the catalytic effect generated by the ability of the metals to switch between two consecutive oxidation states leading to the formation of free radicals, which in turn generate the decomposition of hydroperoxides.

The lability of two COC series, in the presence of transition metal stearates, during the aging process, shows the following degradation order: COC 6013 > COC 8007 > COC $6509>$ COC 8008. Copolymers with tetra cyclododecene comonomer units (Series A, Apel) are more stable to photodegradation than those which have norbornene as the comonomer units (Series D, Topas), and this difference is associated with the percentage of tertiary carbons in their molecular structure.

\section{Conflicts of Interest}

The authors declare that they have no conflicts of interest.

\section{Acknowledgments}

The authors would like to thank M. C. Ma Concepcion Gonzalez and M. C. Marcelina Sanchez Adame for their technical support. One of the authors, Sara A. Zavala-Betancourt, would like to thank CONACYT (National Council of Science and Technology) for a scholarship.

\section{References}

[1] L. F. Doty, Ed., A Brief Overview of Degradable Plastics, Chapman \& Hall, London, 2005.

[2] N. B. Vogt and E. A. Kleppe, "Oxo-biodegradable polyolefins show continued and increased thermal oxidative degradation after exposure to light," Polymer Degradation and Stability, vol. 94, no. 4, pp. 659-663, 2009.

[3] W. L. Hawkins, Polymer stabilization, John Wiley \& Sons, New York, NY, USA, 1972.

[4] G. J. Scott, “Time controlled stabilization of polyolefins," Journal of Polymer Science: Polymer Symposium, vol. 57, pp. 357-374, 1976.

[5] N. C. Billingham and P. D. Calvert, Degradation and stabilization of polyolefins, Applied Science Publishers, London, UK, 1983.

[6] F. Sitek, J. E. Guillet, and M. J. Heskins, "Some aspects of the photolysis and photooxidation of polyethylene containing ketone groups," Journal of Polymer Science: Polymer Symposium, vol. 57, pp. 343-355, 1976.

[7] L. Mingguang, A. R. Horrocks, and M. E. Hall, "Correlation of physicochemical changes in UV-exposed low density polyethylene films containing various UV stabilizers," Polymer Degradation and Stability, vol. 49, pp. 151-161, 1995.

[8] J. L. Pablos, C. Abrusci, I. Marín et al., "Photodegradation of polyethylenes: Comparative effect of $\mathrm{Fe}$ and $\mathrm{Ca}$-stearates as prooxidant additives," Polymer Degradation and Stability, vol. 95, no. 10, pp. 2057-2064, 2010.

[9] T. Ojeda, A. Freitas, K. Birck et al., "Degradability of linear polyolefins under natural weathering," Polymer Degradation and Stability, vol. 96, no. 4, pp. 703-707, 2011.

[10] P. K. Roy, P. Surekha, C. Rajagopa, and V. Choudhary, “Thermal degradation studies of LDPE containing cobalt stearate as prooxidant," Express Polymer Letters, vol. 1, no. 4, pp. 208-216, 2007.

[11] P. K. Roy, P. Singh, D. Kumar, and C. Rajagopal, "Manganese stearate initiated photo-oxidative and thermo-oxidative degradation of LDPE, LLDPE and their blends," Journal of Applied Polymer Science, vol. 117, no. 1, pp. 524-533, 2010.

[12] N. Zalikha, M. Islam, N. Othman, Z. Ahmad, and I. Hanafi, "Effect of pro-degradant additive on photo-oxidative aging of polypropylene film," Sains Malaysiana, vol. 40, pp. 803-808, 2011.

[13] W. Hatke, "Properties and applications of cycloolefin copolymer (COC) films," Kunststoffe, vol. 87, pp. 58-60, 1997.

[14] W. Goerlitz, "Cycloolefin copolymers-new options to meet demanding requirements in films, laminations and extrusion coating," in Proceedings of the 18th European Polymers, Films, Laminations and Extrusion Coatings Conference, pp. 31-37, Barcelona, Spain, 2001.

[15] L. Boggioni and I. Tritto, "State of the art of cyclic olefin polymers," MRS Bulletin, vol. 38, no. 3, pp. 245-251, 2013.

[16] S. Opuszko, H. J. Cook, V. W. Herran, and L. B. McAllister, "Shrink film useful for manufacture of shrink sleeve label," US Patent 20070098933 A1 20070503, 2007.

[17] J. U. Y. Shin, J. I. Y. Park, C. Liu, J. He, and S. C. Kim, "Chemical structure and physical properties of cyclic olefin copolymers (IUPAC technical report)," Pure and Applied Chemistry, vol. 77, no. 5, pp. 801-814, 2005.

[18] M. Avella, E. Bonadies, E. Martuscelli, and R. Rimedio, "European current standardization for plastic packaging recoverable through composting and biodegradation," Polymer Testing, vol. 20 , no. 5, pp. 517-521, 2001.

[19] M. Alauddin, I. A. Choudhury, M. A. El Baradie, and M. S. J. Hashmi, "Plastics and their machining: A review," Journal of Materials Processing Tech., vol. 54, no. 1-4, pp. 40-46, 1995.

[20] M. H. Gutiérrez-Villarreal and S. A. Zavala-Betancourt, "Thermo-Oxidative Stability of Cyclic Olefin Copolymers in the Presence of $\mathrm{Fe}$, Co and Mn Stearates as Pro-Degradant Additives," Polymer - Plastics Technology and Engineering, vol. 53, no. 17, pp. 1804-1810, 2014.

[21] T. C.-K. Yang, S. S.-Y. Lin, and T.-H. Chuang, "Kinetic analysis of the thermal oxidation of metallocene cyclic olefin copolymer (mCOC)/TiO2 composites by FTIR microscopy and thermogravimetry (TG)," Polymer Degradation and Stability, vol. 78, no. 3, pp. 525-532, 2002.

[22] P. K. Roy, P. Surekha, R. Raman, and C. Rajagopal, “Investigating the role of metal oxidation state on the degradation behaviour of LDPE," Polymer Degradation and Stability, vol. 94, no. 7, pp. 1033-1039, 2009.

[23] M. Liu, A. R. Horrocks, and M. E. Hall, "Correlation of physicochemical changes in UV-exposed low density polyethylene films containing various UV stabilisers," Polymer Degradation and Stability, vol. 49, no. 1, pp. 151-161, 1995. 
[24] B. Singh and N. Sharma, "Mechanistic implications of plastic degradation," Polymer Degradation and Stability, vol. 93, no. 3, pp. 561-584, 2008.

[25] F. S. Qureshi, M. B. Amin, A. G. Maadhah, and S. H. Hamid, "Weather-Induced Degradation of Linear Low-Density Polyethylene: Mechanical Properties," Polymer-Plastics Technology and Engineering, vol. 28, no. 7-8, pp. 649-662, 1989.

[26] M. Scoponi, F. Pradella, and V. Carassiti, "Photodegradable polyolefins. Photo-oxidation mechanisms of innovative polyolefin copolymers containing double bonds," Coordination Chemistry Reviews, vol. 125, no. 1-2, pp. 219-230, 1993.

[27] D. Srivastava, P. Kumar, and G. N. Mathur, "Thermo-oxidative degradation studies of ternary blends of polyethylenes," Advances in Polymer Technology, vol. 23, no. 1, pp. 59-70, 2004.

[28] N. S. Allen, M. Edge, D. Holdsworth et al., "Ageing and spectroscopic properties of polyethylenes: comparison with metallocene polymer," Polymer Degradation and Stability, vol. 67, no. 1, pp. 57-67, 2000.

[29] J. V. Gulmine, P. R. Janissek, H. M. Heise, and L. Akcelrud, "Degradation profile of polyethylene after artificial accelerated weathering," Polymer Degradation and Stability, vol. 79, no. 3, pp. 385-397, 2003.

[30] F. Khabbaz, A.-C. Albertsson, and S. Karlsson, "Chemical and morphological changes of environmentally degradable polyethylene films exposed to thermo-oxidation," Polymer Degradation and Stability, vol. 63, no. 1, pp. 127-138, 1999.

[31] N. Z. M. Islam, N. Othman, Z. Ahmad, and H. Ismail, "Effect of pro-degradant additive on photo-oxidative aging of polypropylene film," Sains Malaysiana, vol. 40, no. 7, pp. 803-808, 2011.

[32] P. K. Roy, P. Surekha, C. Rajagopal, S. N. Chatterjee, and V. Choudhary, "Effect of benzil and cobalt stearate on the aging of low-density polyethylene films," Polymer Degradation and Stability, vol. 90, no. 3, pp. 577-585, 2005.

[33] I. Kyrikou, D. Briassoulis, M. Hiskakis, and E. Babou, "Analysis of photo-chemical degradation behaviour of polyethylene mulching film with pro-oxidants," Polymer Degradation and Stability, vol. 96, no. 12, pp. 2237-2252, 2011.

[34] M. Nikolic, E. Gauthier, K. George et al., "Antagonism between transition metal pro-oxidants in polyethylene films," Polymer Degradation and Stability, vol. 97, no. 7, pp. 1178-1188, 2012.

[35] G. Wypych, Handbook of Material Weathering, ChemTec Publishing, Toronto, Canada, 2003.

[36] S. K. Wu, J. Lucki, J. F. Rabek, and B. Rånby, "Photo-oxidative degradation of polynorbornene (part I)," Polymer Photochemistry, vol. 2, no. 1, pp. 73-85, 1982.

[37] H. Al-Madfa, Z. Mohamed, and M. E. Kassem, "Weather ageing characterization of the mechanical properties of the low density polyethylene," Polymer Degradation and Stability, vol. 62, no. 1, pp. 105-109, 1998.

[38] A. C. Tavares, J. V. Gulmine, C. M. Lepienski, and L. Akcelrud, "The effect of accelerated aging on the surface mechanical properties of polyethylene," Polymer Degradation and Stability, vol. 81, no. 2, pp. 367-373, 2003.

[39] M. Salem, "Mechanical properties of UV-irradiated low-density polyethylene films formulated with carbon black and titanium dioxide," Egyptian Journal of Solids, vol. 24, pp. 141-150, 2001.

[40] A. Tanaka, E. Miyagawa, H. Uno, M. Kitamura, and K.-H. Nitta, "Influence of morphology on photo-degradation of low density polyethylene films," Polymer Engineering and Science, vol. 40, no. 9, pp. 2007-2013, 2000.
[41] R. M. Maryudi, A. H. Yunus, M. D. H. Nour, Beg, and M. H. Abidin, "The degradation of high density polyethylene containing manganese stearate under accelerated weathering, presented at the IC-GWBT, 2012," Ahmad Dahlan University, 2012.

[42] A. Ammala, S. Bateman, K. Dean et al., "An overview of degradable and biodegradable polyolefins," Progress in Polymer Science, vol. 36, no. 8, pp. 1015-1049, 2011.

[43] S. Fontanella, S. Bonhomme, J.-M. Brusson et al., "Comparison of biodegradability of various polypropylene films containing pro-oxidant additives based on $\mathrm{Mn}, \mathrm{Mn} / \mathrm{Fe}$ or Co," Polymer Degradation and Stability, vol. 98, no. 4, pp. 875-884, 2013.

[44] M. A. Salem, H. Farouk, and I. Kashif, "Physicochemical changes in UV- exposed low- density polyethylene films," Macromolecular Research, vol. 10, no. 3, pp. 168-173, 2002. 

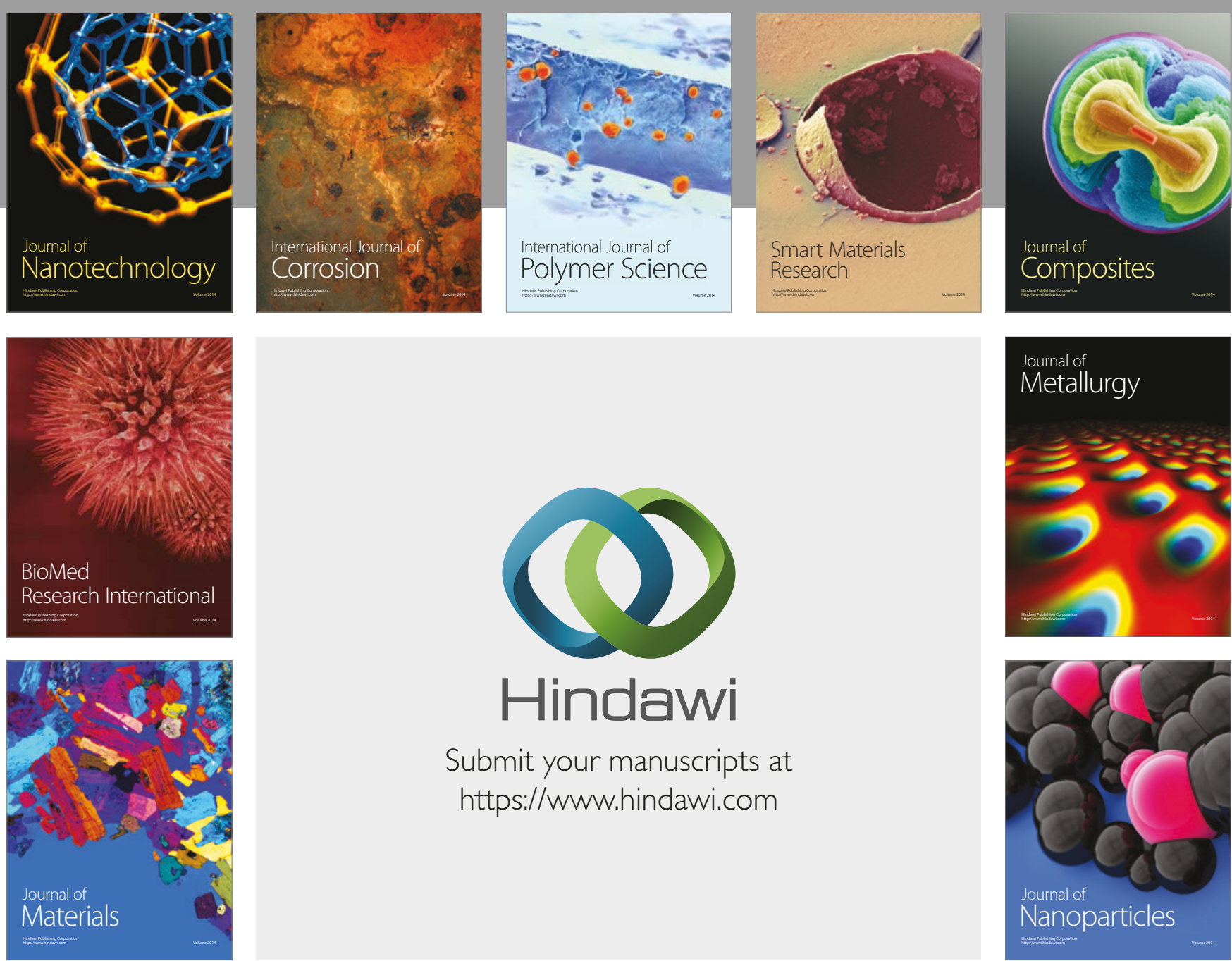

\section{Hindawi}

Submit your manuscripts at

https://www.hindawi.com
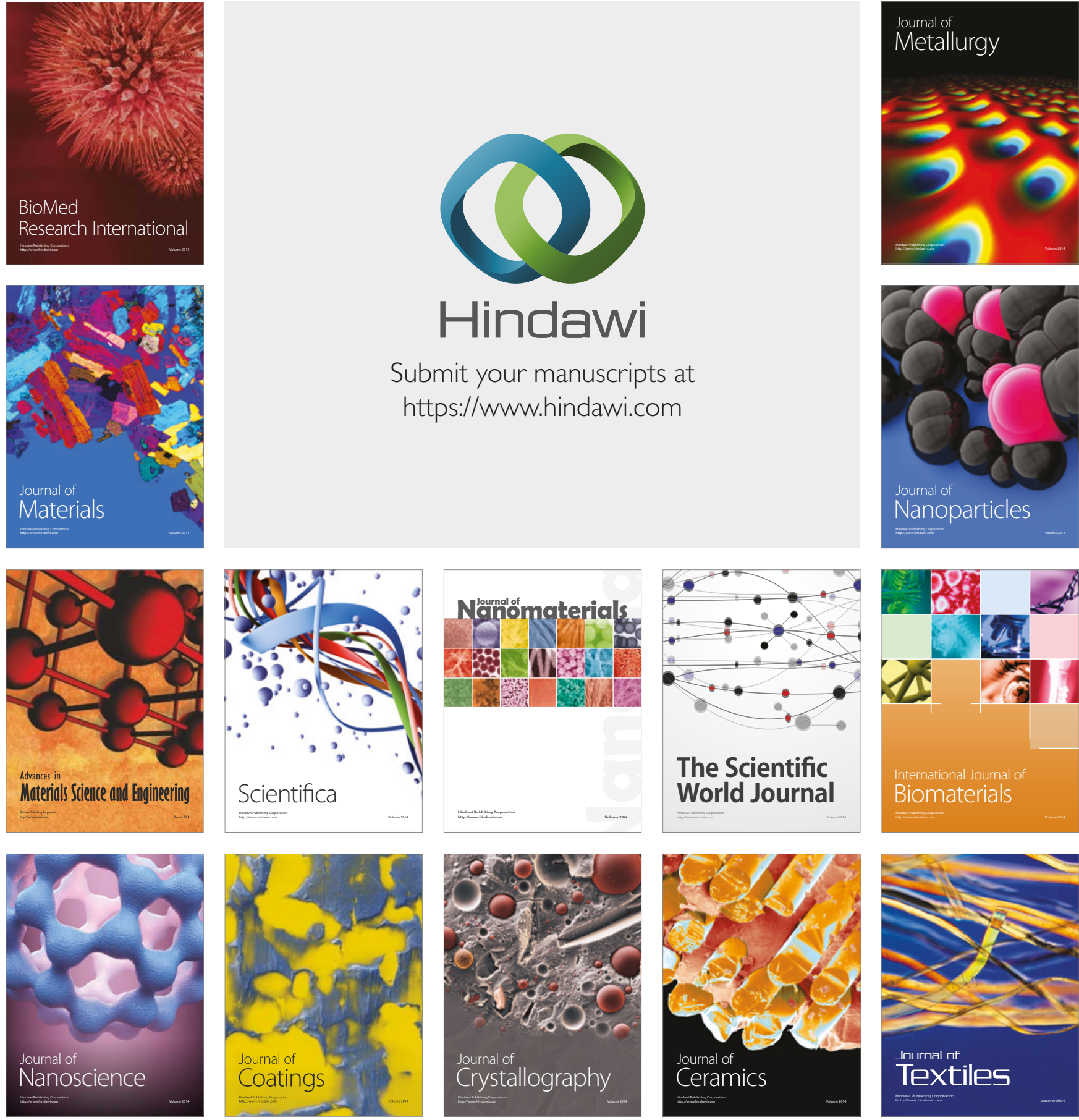

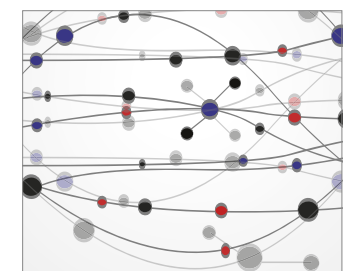

The Scientific World Journal
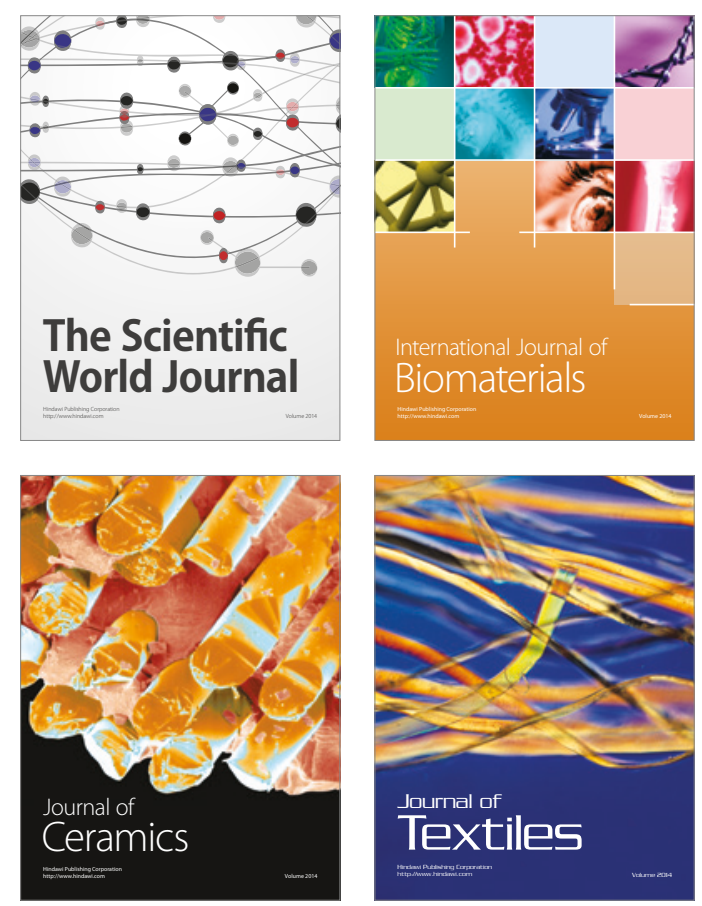